\title{
Experimental results from a stepped frequency GPR
}

\author{
Giovanni Alberti $\left({ }^{1}\right)$, Luca Ciofaniello $\left({ }^{1}\right)$, Giovanni Galiero $\left({ }^{1}\right)$, Raffaele Persico $\left({ }^{2}\right)$, \\ Marco Sacchettino $\left({ }^{1}\right)$, Grazia Maria Signore $\left({ }^{3}\right)$ and Sergio Vetrella $\left({ }^{1}\right)$ \\ ( $\left.{ }^{1}\right)$ CO.RI.S.T.A., Consorzio di Ricerca su Sistemi di Telesensori Avanzati, Napoli, Italy \\ ( $\left.^{2}\right)$ Istituto per il Rilevamento Elettromagnetico dell'Ambiente (IREA), CNR, Napoli, Italy \\ ( $\left.{ }^{3}\right)$ Dipartimento di Beni Culturali dell'Università di Lecce, Italy
}

\begin{abstract}
In the framework of a nationally funded project, a Ground Penetrating Radar (GPR) has been developed by the Italian Consortium for Research on Advanced Remote Sensing Systems (CO.RI.S.T.A.). The system was described in a previous paper (Alberti et al., 2002). As new aspects, the system is a stepped frequency GPR that can work both in gated and ungated mode, and the antennas can be moved automatically in a controlled fashion. As aspects of geophysical interest, the system is exploitable in situations wherein a high resolution and a shallow penetration in the soil (a few meters) are required. Possibly, this is an example of probing a landscape. This paper completes the results of Alberti et al. (2002), wherein laboratory tests where described, by providing the main results obtained during an outdoor experimental campaign, performed first in a controlled site and then in an archaeological site.
\end{abstract}

Key words stepped frequency radar - GPR system

\section{Introduction}

It is well known that the capability of electromagnetic waves to propagate beyond the physical discontinuities of propagation media makes it possible to exploit them to investigate internal features of dielectric bodies. From this property, an endless number of practical applications have arisen, ranging from medical prospecting (Engl et al., 1996) to detection of mines (Rappaport et al., 2000), nondestructive testing of industrial items (Lasri et al., 2000) and GPR applications. GPR applications, in

Mailing address: Dr. Giovanni Alberti, CO.RI.S.T.A., Consorzio di Ricerca su Sistemi di Telesensori Avanzati, Viale Kennedy 5, 80125 Napoli, Italy; e-mail: alberti@ unina.it turn, involve glaciological measurements, research into underground cavities, monitoring of pollutants, probing of landscapes, monitoring of sub-services, archaeological prospecting and so on (Daniels, 1996). In this paper, we are concerned specifically with archaeological prospecting, performed by making use of the GPR system devised by CO.RI.S.T.A. in the framework of a research project (ARCHEO) funded by the Italian MURST (Fiorani et al., 2000). This system was devised after a feasibility study, which also took into consideration different techniques for non invasive prospecting (Esposito et al., 1997). The choice of a Stepped Frequency GPR (SFGPR) was adopted because of several advantages with respect to the traditional impulsive GPR systems. These advantages have been witnessed since the seventies (Robinson et al., 1974; Iizuka et al., 1984; Noon, 1996; Koppenjan et al., 1999; Eisenburger, 2001). In spite of these advantages, most of the commercial systems use 
a design based in time domain. This is probably because the traditional «pulsed» technology is more assessed and currently guarantees, more compact and portable systems. However, we expect that the theoretical possibilities of the SFGPR are worth investigating and exploiting, also due to the fact that technology can progressively reduce the «gap» of compactness and practicality between the pulsed GPR and the SFGPR (Eisenburger, 2001).

The presented radar is equipped with a positioning system (Alberti et al., 2000, 2001) able to move the antennas independently without any human effort: this can decrease the relevance of the weight and compactness of the system.

The GPR system can work both in ungated and gated mode (Stickley et al., 1999). This is in order to have both the possibility to reduce the coupling between the transmitting and receiving antennas (offered by the gated mode) or, if needed, a greater dynamic range (offered by the ungated mode). The latter is kept also because archaeological remains might be found in the shallower layers of the soil, that unavoidably are «lost» with a prospecting in gated mode.

The movement of the antennas is fully programmable in order to gather data automatically in several configurations.

The system has been conceived to experiment new possibilities in GPR prospecting. In particular, with regard to the SFGPR, the programmable movement of the antennas has also allowed inverse scattering multiview techniques (Persico et al., 2000).

This work summarizes the main outdoor experimental results obtained in the framework of ARCHEO (Alberti et al., 2001; Galiero et al., 2003). This completes the description provided in Alberti et al. (2002), where the system and its working modes (ungated and gated) were explained in detail and the first indoor laboratory tests were described. The paper is organized as follows: Section 2 provides a brief description of a stepped frequency GPR and the gated and ungated modes; Section 3 deaks with outdoor tests performed in a controlled site are exposed; Section 4 describes a real archaeological site where additional tests have been performed. The results of these additional tests are given in Section 5. Conclusions follow.

\section{The stepped frequency GPR}

This section briefly outlines what a Stepped Frequency GPR (SFGPR) is, and what the gated and ungated modes are. An SFGPR is a GPR system radiating a succession of harmonic signals rather than an impulsive signal. Since the soil can be regarded as a time-invariant system, and since the received signal is a linear function of the incident one, an SFGPR essentially retrieves a sampling of the harmonic answer of the underground scenario, whereas a classical GPR provides a sampling of the impulsive answer of the underground scenario. It is well known that the harmonic answer and the impulsive answer of a linear time invariant system are mathematically equivalent and, in particular, they are linked to each other between a Fourier Transform. However, from a practical point of view, gathering the harmonic answer rather than the impulsive answer offers some advantages (Noon, 1996). In fact, a greater energy can be processed without increasing the maximum level of the signal (which would provide the saturation of the receiver), on condition that the duration of the signal is made longer. At the same time, the longer duration of the harmonic input signal reduces its band decreasing the thermal noise at the receiver. This makes the signal to noise ratio increase. Moreover, measuring the harmonic answer, the technological specifics on the receiver are less severe because, thanks to heterodyne demodulation procedures, one can sample the received (base-band) signal at a rate much lower than that needed in the case of an impulsive GPR. On the other hand, an SFGPR imposes that attention is devoted to the problem of the aliasing due to the sampling of the harmonic answer. This is resolved with a frequency step small enough (usually of the order of a few $\mathrm{MHz}$ ), which can slow down the gathering of the data.

The «normal» working mode of a SFGPR is conceived such as the transmitting and the receiving antennas are both switched on. This working mode is more specifically called «ungated». In order to decrease the undesired signal due to the direct coupling between the antennas, some systems are conceived such as the receiving antenna is switched off while the 
transmitting antenna is switched on and vice versa. This working mode is more specifically called «gated». In gated mode, the coupling of the antenna is eliminated, but the price paid is a loss of the first part of answer of the underground scenario, related to the shallower parts of the soil. Moreover, the receiving chain is inherently more complicated and the signal to noise ratio available is in general lower. In some situations, this price is not severe. However, in cases where the objects buried are shallow, the gated mode «kills» just the relevant part of the answer of the underground scenario. This can be the case in archaeological prospections wherein, some times, it is known a priori that the finds are within the depth of one meter. For this reason, the GPR system exploited in this paper can work both in ungated and gated modes.

\section{Outdoor tests in a controlled site}

This section describes outdoor tests on the GPR in a controlled site, performed after laboratory tests (Alberti et al., 2002). In order to calibrate the system and assess its performances, a dedicated outdoor test facility was set up. In the framework of an agreement with the Italian Aerospace Research Centre (CIRA) located in Capua (Southern Italy), within its establishment, a $25 \times 25 \mathrm{~m}^{2}$ pool with a depth of $5 \mathrm{~m}$ was built and filled with river sand. Several objects, such as metallic sheets, plastic pipes, and tanks at different depths were buried as reference targets.

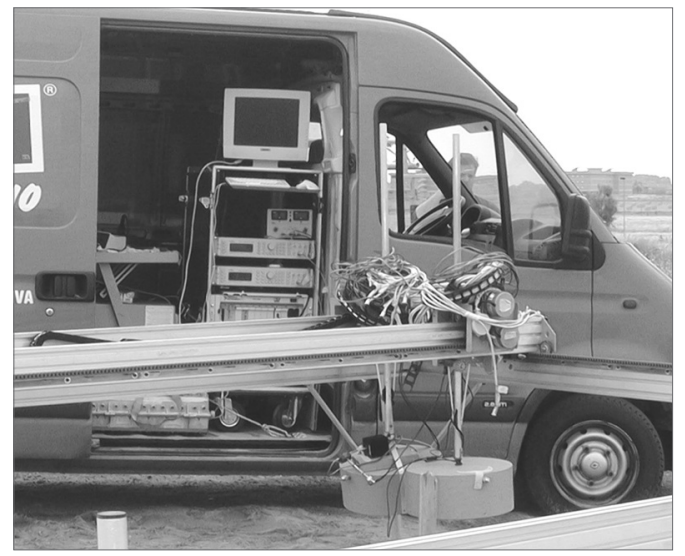

Fig. 1. The rack of the GPR inside the van during data acquisition campaign.

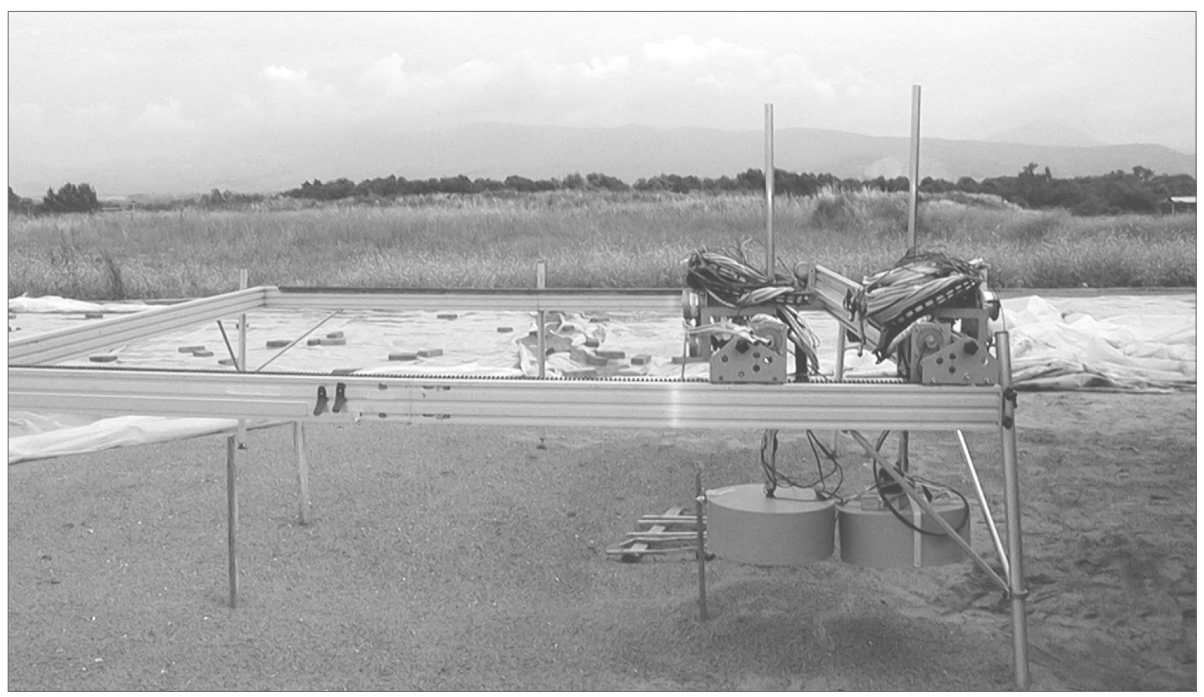

Fig. 2. The antennas positioning system during the campaign on the sand pool. 
A portion of the pool and the experimental set-up of the stepped frequency GPR are shown in figs. 1 and 2 respectively. Figure 1 shows the rack (within the van) where the whole radar system is accommodated, and fig. 2 gives a particular of the antennas positioning system. Figure 3 shows the obtained image of a metallic sheet $\left(1 \times 2 \mathrm{~m}^{2}\right.$ wide) placed at $50 \mathrm{~cm}$ of depth. In fig. 3 and in the successive figures, the vertical axis represents the return time, in seconds, with respect to the equivalent synthetic pulse, whereas the horizontal axis is the spatial co-ordinate expressed in the index of the consequent positions (the spatial step in centimeters between consecutive data, however, will be always provided apart in the text). For the example of fig. 3, the transmitting and receiving antennas were moved in linear common offset along the direction orthogonal to the shorter side of the sheet, by keeping a

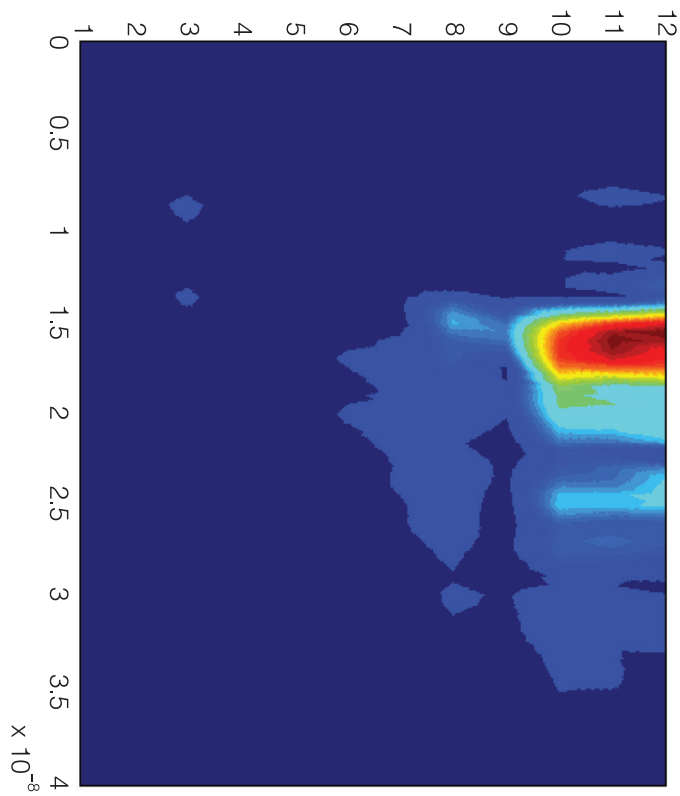

Fig. 3. Image of a metal sheet at $50 \mathrm{~cm}$ of depth in ungated mode. Linear common offset (distance between the gaps of $55 \mathrm{~cm}$ ). Wideness of the sheet of $1 \mathrm{~m}$. Frequency band of 200-800 MHz. Frequency step of $2 \mathrm{MHz}$. The abscissa is the number of scan with spatial step $20 \mathrm{~cm}$. The ordinate is the return time in seconds. distance of $55 \mathrm{~cm}$ between the antennas. This distance has been kept unchanged for all the measurements described in the present paper and it is the result of a trade-off between the levels of the direct antenna leakage and of the received signal. The measurements of fig. 3 were started at $110 \mathrm{~cm}$ before the sheet edge and the antennas were moved into 12 subsequent scans with a step of $20 \mathrm{~cm}$. At any position, the frequency band transmitted was from 200 up to $800 \mathrm{MHz}$ with a frequency step of $2 \mathrm{MHz}$. The GPR worked in ungated mode. No particular signal processing (Conyers et al., 1997) was applied to the GPR data, apart from the mandatory IFFT to obtain the synthetic pulses from the data gathered in the frequency domain. In spite of this, we can appreciate a very good resolution.

Figure 4 shows the image of the same metallic sheet, but deeper $(1.2 \mathrm{~m})$. The modality of the

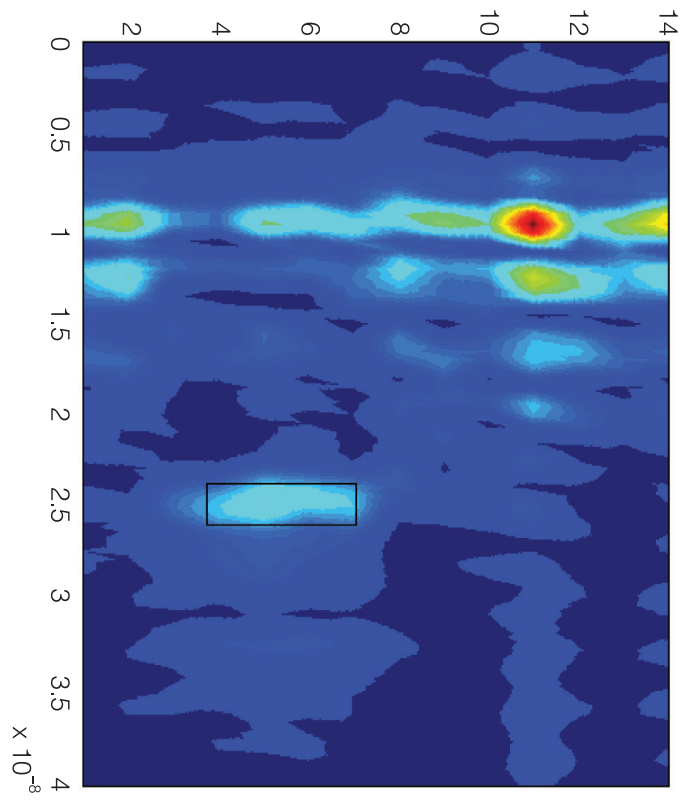

Fig. 4. Image of a metal sheet at $120 \mathrm{~cm}$ of depth in ungated mode. Linear common offset (distance between the gaps of $55 \mathrm{~cm}$ ). Width of the sheet of $1 \mathrm{~m}$. Frequency band of 200-800 MHz. Frequency step of $2 \mathrm{MHz}$. The abscissa is the number of scan with spatial step $20 \mathrm{~cm}$. The ordinate is the return time in seconds. 


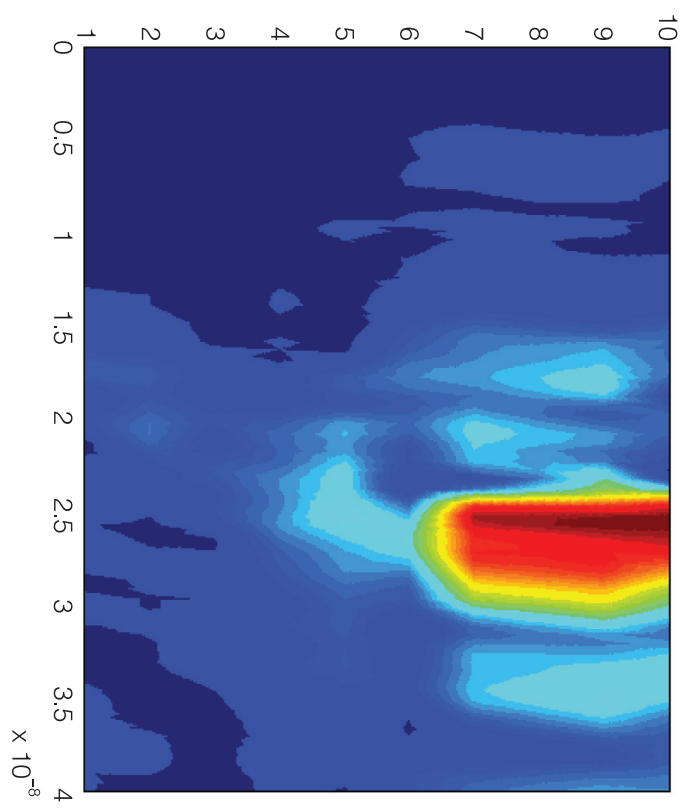

Fig. 5. Image of the same metal sheet of fig. 4 in gated mode (performed by discharging the first 3 ns of depth). Linear common offset (distance between the gaps of $55 \mathrm{~cm}$ ). Frequency band of $200-800 \mathrm{MHz}$. Frequency step of $2 \mathrm{MHz}$. The abscissa is the number of scan with spatial step $25 \mathrm{~cm}$. The ordinate is the return time in seconds.

scan was kept unchanged with respect to the previous scan (in particular the spatial step and the frequencies) with the only differences that 14 scans were made and the measure started about $60 \mathrm{~cm}$ before the sheet edge. This time the sheet (evidenced by a rectangular frame) appears as a weaker signal with respect to the direct coupling signal between the antennas. This coupling discloses a sort of false layer at the temporal depth of $10 \mathrm{~ns}$ wherein a ghost target toward the right hand side is particularly evident. This had not happened with the shallower sheet because the stronger returns from the target covered the coupling signal (the map of colors refers always to a normalized graph). In the case of the deeper sheet a scan in gated mode can be helpful, because it should avoid the false returns due to the direct coupling between transmitting and receiving antenna.

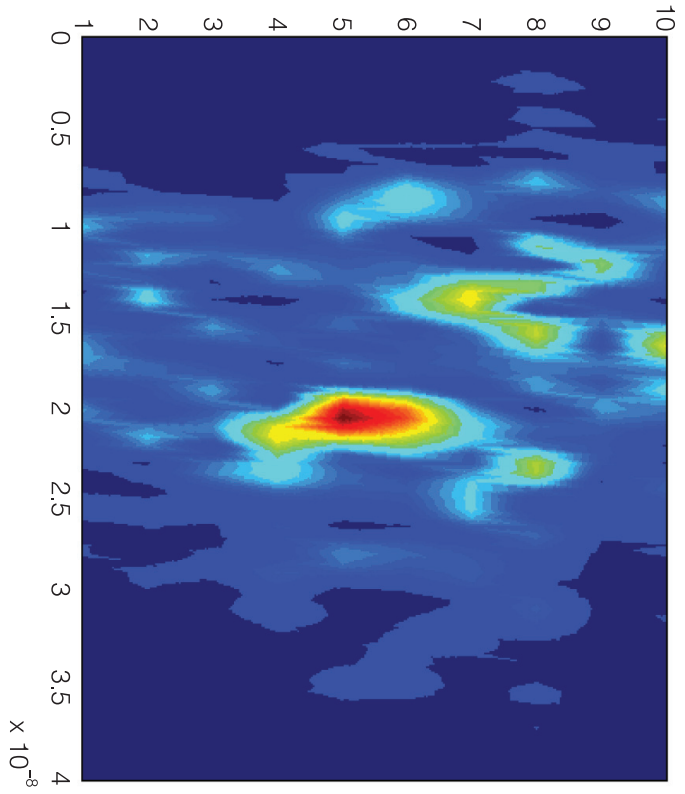

Fig. 6. Image of a metal pipe at $80 \mathrm{~cm}$ of depth in ungated mode. Linear common offset (distance between the gaps of $55 \mathrm{~cm}$ ). Diameter of the pipe of $80 \mathrm{~cm}$. Frequency band of 200-800 MHz. Frequency step of $2 \mathrm{MHz}$. The abscissa is the number of scan with spatial step $20 \mathrm{~cm}$. The ordinate is the return time in seconds.

Therefore, a B-scan in gated mode on the same target was performed. The result is shown in fig. 5, wherein the false target due to the coupling disappears. The B-scan was performed on 10 spatial positions, stepped $25 \mathrm{~cm}$ from each other. The gated mode was implemented by considering 10 non-overlapping layers of $10 \mathrm{~ns}$ and then by retaining the comprehensive response of the seven deeper layers. This result shows the usefulness of having at disposal both the ungated and gated modes: if the image obtained in ungated mode «generates some doubts» a different image in gated mode might «clarify» these doubts.

Let us now show some further results with different kinds of targets. In the following tests we used the ungated mode again. Figure 6 shows a B-scan on a metallic pipe. The measures were taken in 10 subsequent positions, spaced $20 \mathrm{~cm}$, 


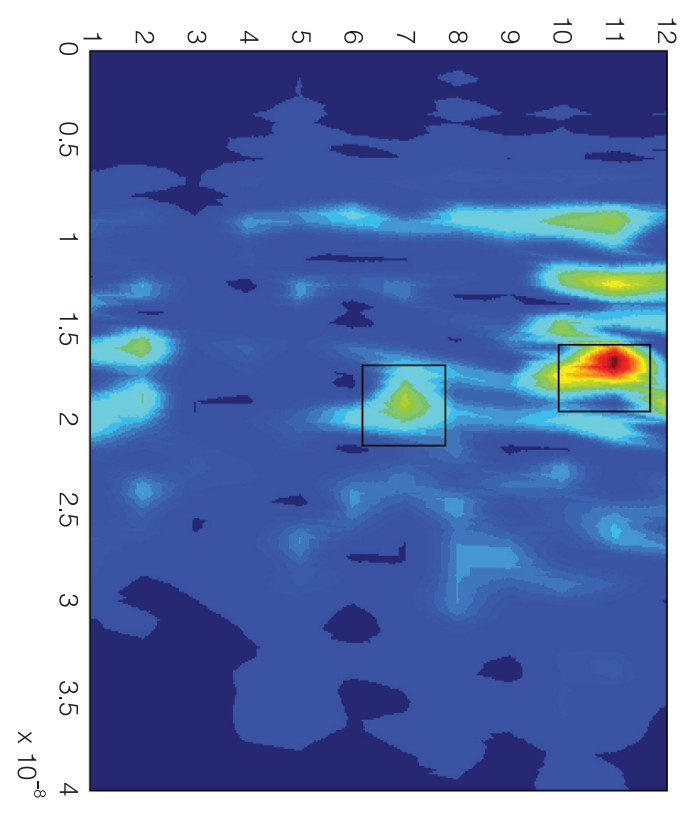

Fig. 7. Image of two parallel empty plastic pipes at 85 $\mathrm{cm}$ of depth in ungated mode. Linear common offset (distance between the gaps of $55 \mathrm{~cm}$ ). Diameter of the pipes of $40 \mathrm{~cm}$. Distance between the axes of the pipes of $60 \mathrm{~cm}$. Frequency band of 200-800 MHz. Frequency step of $2 \mathrm{MHz}$. The abscissa is the number of scan with spatial step $20 \mathrm{~cm}$. The ordinate is the return time in seconds.

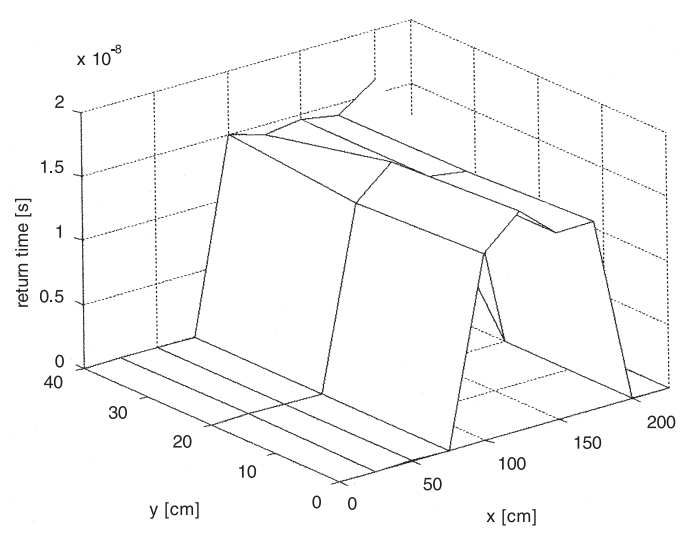

Fig. 8. Planar scans of the return times of the meaningful radar pulses for the metal sheet of fig. 3 . starting $135 \mathrm{~cm}$ before the pipe axis. The pipe is placed at $80 \mathrm{~cm}$ depth. It has a diameter of 80 $\mathrm{cm}$, is about $1 \mathrm{~m}$ long with its axis parallel to the air soil interface. The object is clearly visible, and the strength of the signal returned from it masks the coupling signal. Figure 7 shows the result of a scan performed on a couple of pipes parallel to each other and with the axis parallel to the interface between air and soil. The two pipes (shown by rectangular frames) are made of plastic and are empty. Their depth is $85 \mathrm{~cm}$, they are 3 $\mathrm{m}$ long and have a diameter of $40 \mathrm{~cm}$ and their axes are $60 \mathrm{~cm}$ between each pipe. The spatial step was set to $20 \mathrm{~cm}$. The difference between the strengths of the returned signals from the two pipes is probably due to the nearness of the bound of the pool to the right pipe. This fact might also influence the difference in the apparent depth of the two reconstructed pipes.

Finally, fig. 8 shows some results regarding a common offset planar scan on the same metal sheet of fig. 3. This planar scan is composed of 3 B-scans spaced $20 \mathrm{~cm}$, each of which composed of 10 A-scans with a spatial step of $25 \mathrm{~cm}$.

More precisely, fig. 8 shows a plot of the times of the maxima of the meaningful radar returns for each position of the planar scan. As a criterion to state the meaningfulness of the returned pulse, a threshold of $60 \%$ with respect of

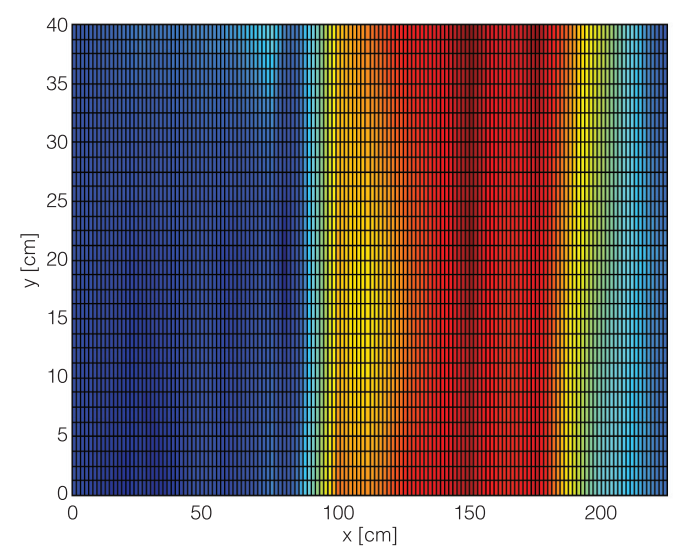

Fig. 9. Planar horizontal image of the metal sheet at 50 $\mathrm{cm}$ of depth corresponding to the return time of $15 \mathrm{~ns}$. 
the amplitude of the more intense returned pulse was adopted.

This visualization can provide an aid when a meaningful and geometrically localized planar interface is met. Another visualization can be provided by representing in a color graph the values of the received pulses after $15 \mathrm{~ns}$ at all the positions of the planar scan, i.e. an image slice at a fixed depth (Conyers et al., 1997; Leucci et al., 2002). The result is shown in fig. 9, wherein the data have been linearly interpolated.

\section{The archaeological site of Cales}

External tests on a real archaeological site, authorized by the «Soprintendenza Archeologica di Napoli e Caserta», were performed with the assistance of archaeologists, to perform a prospecting driven by «real» archaeological problems, and not only a mere technical test on the GPR.

The archaeological site at hand is constituted by the ruins of the ancient Roman town of Cales, located in a tufaceous plateau at about $50 \mathrm{~km}$ north of Naples (Southern Italy). The area of Cales is currently exploited for agricultural purposes and this makes the enforcement of a proper protection program difficult. Some of the buildings of the ancient town are only partially covered and their structures are partially hidden at a shallow depth. Therefore, this archaeological site has represented a good setting to test the new instruments generated in the framework of ARCHEO, because the ancient objects partially buried represented a good calibration tool.

The Romans founded Cales in the year 334 B.C. (this piece of information has been handed down from the Latin historians Titus Livius in his book Ab Urbe Condita (VIII, 16, 11-14) and Velleius Paterculus in Historiae Romanae (I, 4, 3)) on a preexisting village of the indigenous people of the Ausons (Johannowsky, 1961; Gasparetti et al., 1999).

The urban structure of Cales has never been investigated systematically. However, several pieces of the ancient town have been identified. In particular, pieces of the walls of the town, the necropolis with some monumental tombs, the so-called «Central Baths», an amphitheater and a second bath building have been located
(Gasparetti et al., 1999). These finds are dated, depending on the particular find, from the end of the 2 nd century B.C. up to the 2 nd century A.D. On the west side of the Central Baths there is a lane (still used today) identified as the northsouth main street (the so-called cardo maximus) of the Roman town. Beyond the lane, a theater dated at the beginning of the 1st century B.C. (but modified during the reign of Julius Caesar Augustus (29 B.C.-14 A.D.) has been recently excavated (De Caro, 2000).

The GPR was tested in the vicinity of this theater, whose plan is given in fig. 10 .

Excavations performed by the «Soprintendenza Archeologica di Napoli e Caserta» in the year 1999 brought to light, on the southwest side of this monument, part of a road made with flagstones. This road is labeled with an $\mathrm{S}$ in fig. 10. Probably, it used to lead into the theater (De Caro, 2000). The road has never been thoroughly excavated and, at the moment, we do not know the whole of its path.

We performed some prospecting toward northwest and south along the known part of the path to investigate its possible direction.

The results of the measurements performed at a few meters of distance from the southern bound of the road, in squares A and B of fig. 10, and the results of the measurements gathered further southward, beyond the current street labeled S1, in square $\mathrm{C}$ of fig. 10 are shown.

In the area of squares $\mathrm{A}$ and $\mathrm{B}$, the direction of the Roman road under the current soil level had already been verified by excavation tests, and then covered again. Therefore this area was suitable to test the instrument. In the case of square $\mathrm{C}$, instead, no previous test was available. Therefore, the purpose of that prospecting was to inquire about a possible straight continuation of the road beyond the area of the theater (which is implicitly an investigation on possible relationships between the current and the ancient layout of the roads of Cales).

\section{Experimental results at Cales}

With reference to fig. 10, let us now show the result of a prospecting performed in square A. The prospecting was in planar common offset, 


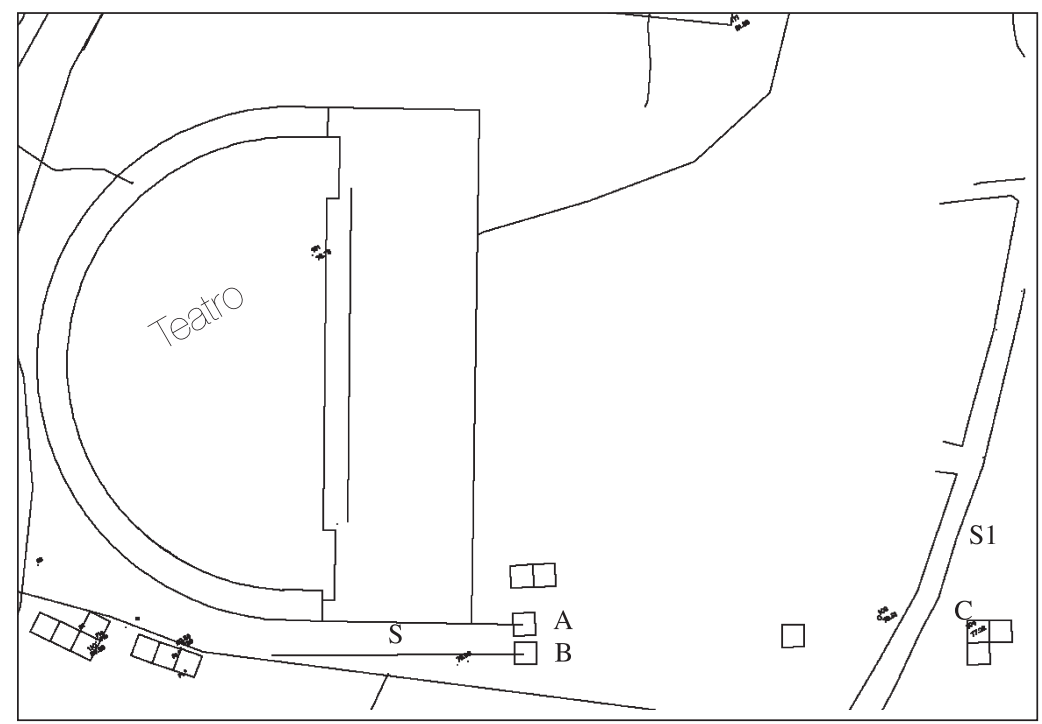

Fig. 10. Plan of the area of the Roman theatre of Cales.

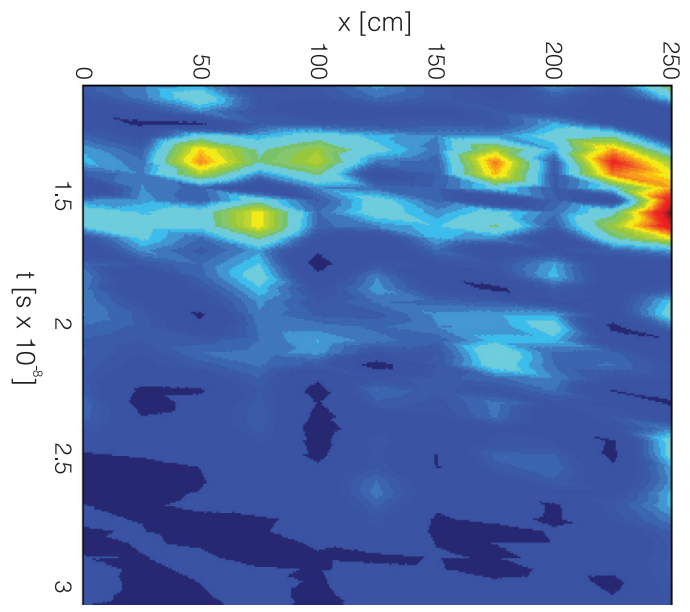

Fig. 11. Prospecting in linear common offset on a buried Roman road.

with 4 B-scans (Daniels, 1996) parallel to each other and $70 \mathrm{~cm}$ apart. Along each B-scan, the antennas were placed in 11 positions with a spatial step of $25 \mathrm{~cm}$. The distance of the gaps of the two antennas was $55 \mathrm{~cm}$. The exploited

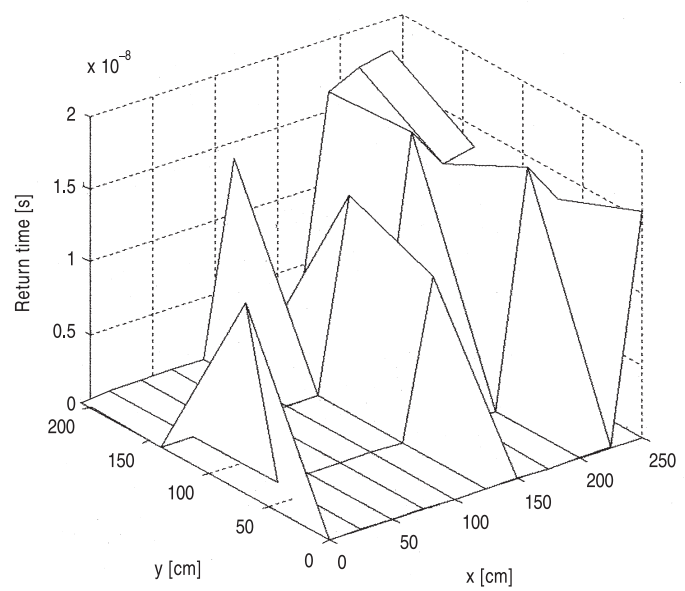

Fig. 12. Planar interpolation of the meaningful return times on the Roman road (square A).

band was from 200 to $800 \mathrm{MHz}$, with a frequency step of $2 \mathrm{MHz}$ (this band and this frequency step were maintained in all the further prospecting shown in the following). Figure 11 represents one of these $4 \mathrm{~B}$-scans, performed such as the 


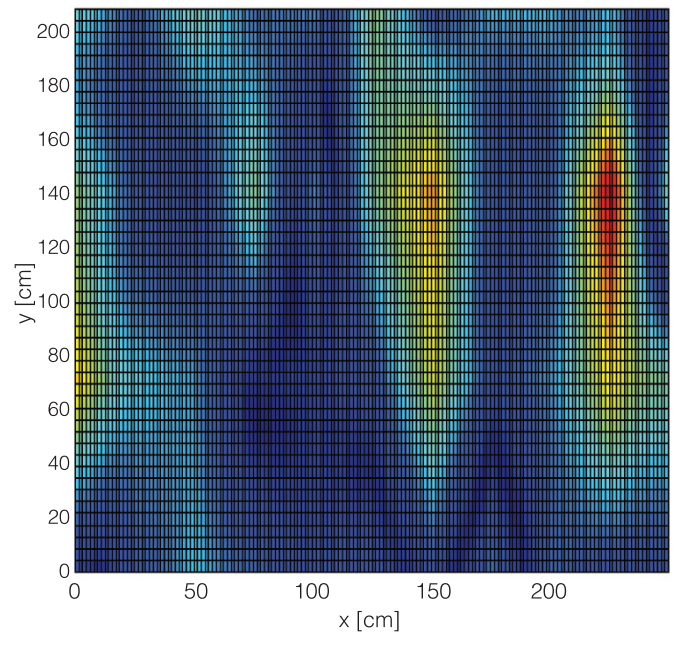

Fig. 13. Horizontal slice at 12 ns under the Roman road (square A).

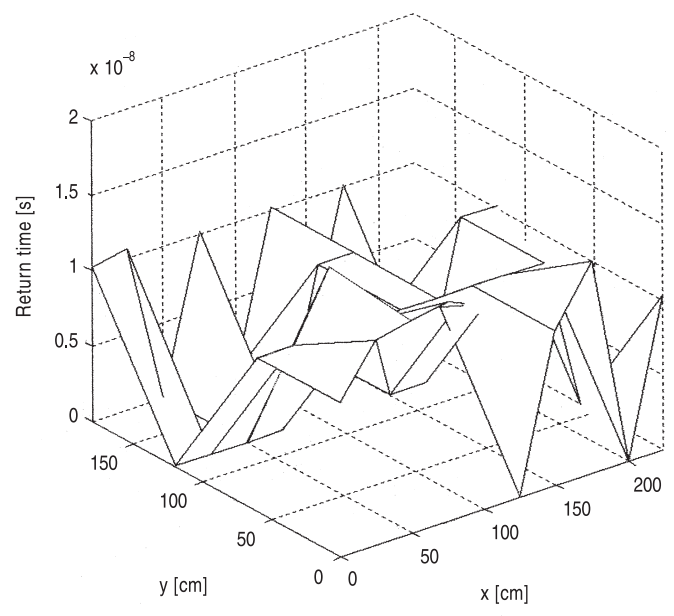

Fig. 15. Planar interpolation of the meaningful return times outside the theatre area (square C).

final positions were corresponded to the ancient road (that we know to be at a depth of about $40 \mathrm{~cm}$ ). From the intensity of the colors, it can be noted how this feature results. To provide a comprehensive idea, an interpolation of the

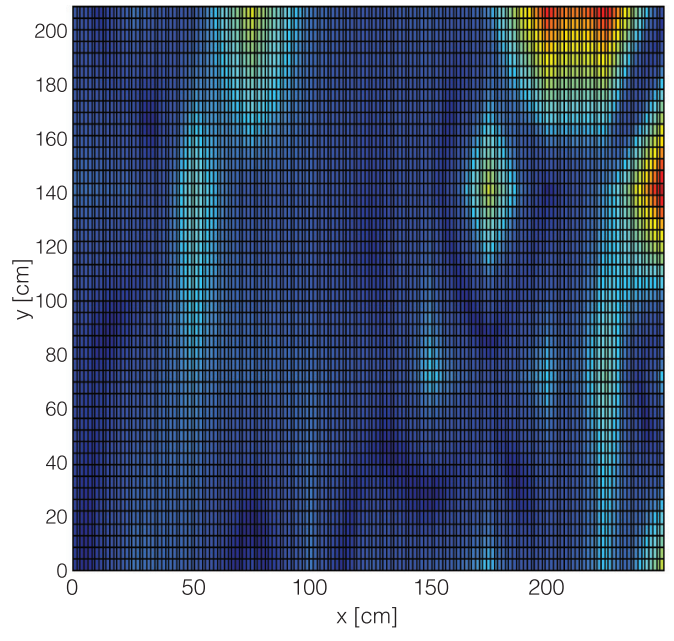

Fig. 14. Horizontal slice at $15 \mathrm{~ns}$ under the Roman road (square A).

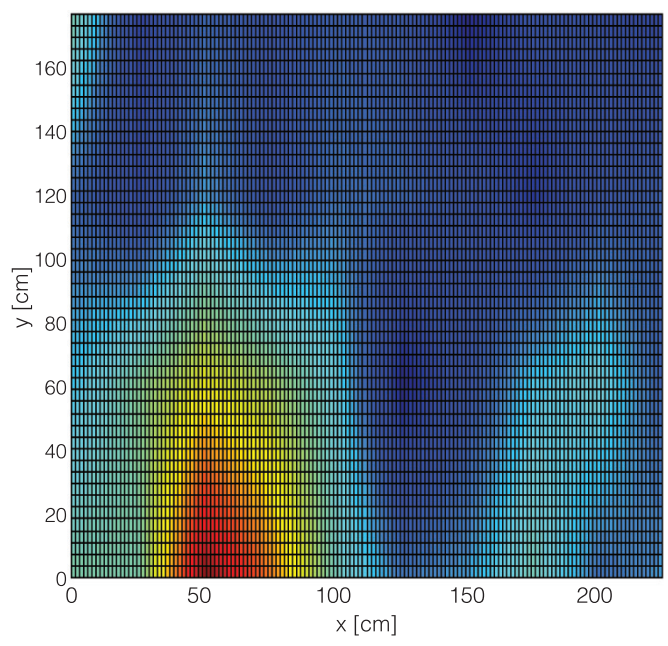

Fig. 16. Horizontal slice at $15 \mathrm{~ns}$ outside the theatre area (square C).

meaningful returns was done, realized in the same way as fig. 8. The result is shown in fig. 12 , wherein one can appreciate how in each of the $4 \mathrm{~B}$-scans the meaningful returns were in the final part of the line, i.e. over the road. Another 
visualization was obtained by a horizontal slice at 12 ns (fig. 13) and 15 ns (fig. 14). Figures 13 and 14 were obtained with a linear interpolation of the data available, in the same way as fig. 9. Again a stronger signal in correspondence with the road can be noted in both fig. 13 and fig. 14. An analogous scan was performed in square B, wherein the other side of the road was investigated. The results (not reported for brevity) confirmed the evidence shown for the square A.

Let us now show some results obtained in square $\mathrm{C}$, which is aligned with a hypothetical continuation of the road $\mathrm{S}$ along a straight path (prolonged hypothetically beyond the lane S1). A planar scan made up of 4 parallel B-scans $60 \mathrm{~cm}$ apart were performed. In each B-scan, the data were gathered in 10 positions, spaced $25 \mathrm{~cm}$.

Figure 15 shows the interpolation of the meaningful maxima. There are returns spread all over the square, but this figure does not disclose precisely an area more meaningful than others (in this case the interpolation of the meaningful return time is not helpful). Figure 16, instead, shows a horizontal slice at the depth of $15 \mathrm{~ns}$ : this time a meaningful signal can be noted on the lower left side of the image. This makes us think of a localized reflection. It seems likely that we are not in the presence of a planar reflecting structure as that of fig. 12. In fact, the answer of the instrument is quite different from that obtained in squares A and B. In other words, the road $\mathrm{S}$ does not seem to continue along a straight line beyond the current lane S1. In the end, it is likely that lane $\mathrm{S} 1$, like the cardo maximus, is also a current path superimposed on an ancient Roman road. However, the truth of such a conjecture, and in particular the nature of the reflection disclosed by fig. 16, can be clarified only by archaeological excavation.

\section{Conclusions}

This paper summarized the main outdoor tests performed with a SFGPR system realized by CO.RI.S.T.A. As new aspects, the system can work both in ungated and gated mode and it is equipped with a positioning system able to move the antennas automatically and independently.
The tests were performed first in a controlled site and then in a real archaeological site. The prospecting in the real archaeological site was performed with the assistance of two archaeologists, and in particular real archaeological questions were addressed.

\section{Acknowledgements}

The work described in this paper has been totaly funded by the Italian «Ministero dell'Università e della Ricerca Scientifica e Tecnologica (MURST)».

Moreover, we sincerely thank the «Soprintendenza Archeologica di Napoli e Caserta», which allowed the experimentation of the GPR at Cales.

\section{REFERENCES}

Alberti, G., L. Ciofaniello, M. Della Noce, S. EsPosito, G. Galiero, R. Persico and S. Vetrella (2000): Advanced stepped frequency GPR development, in Proceedings of the Conference on Subsurface Sensing Technologies and Applications II, at SPIE's Annual Meeting, San Diego, U.S.A., 484-492.

Alberti, G., L. Ciofaniello, G. Galiero, R. Persico, M. SACChettino and S. Vetrella (2001): A stepped frequency GPR system working both in ungated and gated mode, in Proceedings of Workshop on «Remote Sensing by Low-Frequency Radars», Napoli (Italy), 20-21 September 2001, Session 3 (online publication).

Alberti, G., L. Ciofaniello, M. Della Noce, S. Esposito, G. Galiero, R. Persico, M. Sacchettino and S. Vetrella (2002): A stepped frequency GPR system for underground prospecting, Ann. Geophysics, 45 (2), 375-391

Conyers, L.B. and D. Goodman (1997): Ground Penetrating Radar: an Introduction for Archaelogists (Alta Mira Press, Walnut Creek, CA), pp. 232.

DANIELS, D.J. (1996): Surface-penetrating radar, in IEE Radar, Sonar, Navigation and Avionics, edited by E.D.R. SHARMAN and P. BRADSELL (Exeter, United Kingdom, Short Run Press Ltd.), Series 6, pp. 300.

DE CARO, S. (2000): L'attività archeologica della Soprintendenza di Napoli e Caserta nel 2000, in ACT $X L, 895-897$.

EISENBURGER, D., V. DAMM and H. LENTZ (2001): Helicopterborne GPR system for geological applications. A comparison between pulse radar and stepped frequency radar, in Proceedings of Workshop on «Remote Sensing by Low-Frequency Radars», Napoli (Italy), 20-21 September 2001, Session 2 (online pubblication). 
ENGL, H.W., A.K. LouIS and W. RUNDELL (1996): Inverse problems in medical imaging and nondestructive testing, in Proceedings of the Conference in Oberwolfach, Federal Republic of Germany, February 4-10, 1996 (Springer-Verlag Wien, New York), pp. 211.

ESPOSITO, S. and M. BORTONE (1997): Tecniche e sensori per lo studio del sottosuolo, CO.RI.S.T.A. Technical Report A11-COR/NT/002.

Fiorani, L., M. Bortone, S. Mattei, C. Ruocchio, A. SALOMÉ and S. VETRELLA (2000): GEOSCOPE and GEOLIDAR: integrated instruments for underground archaeological investigations, Subs. Sens. Tech. Appl., 1, 305-318.

Galiero, G., R. Persico, M. Sacchettino and G.M. SIGNORE (2003): Nuove tecniche di prospezione archeologica mediante strumenti multifrequenza, Thalassia Salentina (in print).

Gasperetti, G., C. Passaro and S. De Caro (1999): Novità dal territorio degli Ausoni, in Magna Grecia e Sicilia. Stato degli Studi e Prospettive di Ricerca. Atti dell'Incontro di Studi, Messina, 2-4 Dicembre 1996, edited by M. BArRa Bagnasco, E. DE Miro and A. PINZONE (Di.Sc.A.M., Messina), 145-158.

JOHANNOWSKY, W. (1961): Relazione preliminare sugli scavi di Cales, Bollettino d'Arte, s. IV, XLVI, 258-268.

Koppenjan, S.K., C.M. AlLEN, D. GARDNER, H.R. WonG, H. LEE and S.J. LOCKWOOD (1999): Multi-frequency synthetic-aperture imaging with a lightweight ground penetrating radar system, J. Appl. Geophys., 43 (2/4), 252-258.

IizuKA, K., A.P. Freundorfer, K.H. Wu, H. Mori, H. OGURA and V.-K. NGUYEN (1984): Step frequency radar, J. Appl. Phys., 56 (9), 2572-2583.
Lasri, T., D. Glay, L. Achrait, A. Mamouni and Y. LEROY (2000): Microwave methods and systems for nondestructive control, Subs. Sens. Tech. Appl., 1, 141-160.

LEUCCI, G., S. Negri, M.T. CARROZZO and L. NuZZO (2002): Use of ground penetrating radar to map subsurface moisture variations in an urban area, J. Environ. Eng. Geophys., 7 (2), 69-77.

Noon, D.A. (1996): Stepped-frequency radar design and signal processing enhances ground penetrating radar performance, Ph.D. Thesis, Department of Electrical and Computer Engineering, University of Queensland, Australia.

Persico, R., G. Alberti, S. Esposito, G. Leone and F. SOLDOVIERI (2000): On multifrequency strategies of use of GPR systems, in Proceedings of the Conference on Image Reconstruction from Incomplete Data, at SPIE's Annual Meeting, San Diego, U.S.A., 26-34.

Rappaport, C.M., M. Silevitch, S. McKnight, C. DiMarzio, E. Miller and H. RaEmer (2000): Multi-mode subsurface sensing and imaging for land mine detection, in Proceedings of The Conference on Subsurface Sensing Technologies and Applications II, at SPIE's Annual Meeting, San Diego, U.S.A., 2-10.

ROBINSON, L., W.B. WEIR and L. YUNG (1974): Location and recognition of discontinuities in dielectric media using synthetic RF pulses, Proceeding IEEE, 62 (1), 36-44.

Stickley, G.F., D.A. NoOn, M. Cherniakov and I.D. LONGSTAFF (1999): Gated stepped-frequency ground penetrating radar, J. Appl. Geophys., 43 (2/4), 259-269.

(received March 3, 2003; accepted Juy 7, 2003) 